\title{
Reliable intraocular pressure measurement using automated radio-wave telemetry
}

This article was published in the following Dove Press journal:

Clinical Ophthalmology

7 January 2014

Number of times this article has been viewed

\section{Eleftherios I Paschalis* \\ Fabiano Cade* \\ Samir Melki \\ Louis R Pasquale \\ Claes H Dohlman \\ Joseph B Ciolino}

Massachusetts Eye and Ear Infirmary, Harvard Medical School, Boston, MA, USA

*These authors contributed equally to this work
Correspondence: Joseph B Ciolino Massachusetts Eye and Ear Infirmary, 243 Charles Street, Boston,

MA, 02। I4, USA

Email Joseph_Ciolino@MEEl.HARVARD. EDU
Purpose: To present an autonomous intraocular pressure (IOP) measurement technique using a wireless implantable transducer (WIT) and a motion sensor.

Methods: The WIT optical aid was implanted within the ciliary sulcus of a normotensive rabbit eye after extracapsular clear lens extraction. An autonomous wireless data system (AWDS) comprising of a WIT and an external antenna aided by a motion sensor provided continuous IOP readings. The sensitivity of the technique was determined by the ability to detect IOP changes resulting from the administration of latanoprost $0.005 \%$ or dorzolamide $2 \%$, while the reliability was determined by the agreement between baseline and vehicle (saline) IOP.

Results: On average, 12 diurnal and 205 nocturnal IOP measurements were performed with latanoprost, and 26 diurnal and 205 nocturnal measurements with dorzolamide. No difference was found between mean baseline IOP $(13.08 \pm 2.2 \mathrm{mmHg})$ and mean vehicle IOP $(13.27 \pm 2.1 \mathrm{mmHg})(P=0.45)$, suggesting good measurement reliability. Both antiglaucoma medications caused significant IOP reduction compared to baseline; latanoprost reduced mean IOP by $10 \%(1.3 \pm 3.54 \mathrm{mmHg} ; P<0.001)$, and dorzolamide by $5 \%(0.62 \pm 2.22 \mathrm{mmHg}$; $P<0.001)$. Use of latanoprost resulted in an overall twofold higher IOP reduction compared to dorzolamide $(P<0.001)$. Repeatability was $\pm 1.8 \mathrm{mmHg}$, assessed by the variability of consecutive IOP measurements performed in a short period of time ( $\leq 1$ minute), during which the IOP is not expected to change.

Conclusion: IOP measurements in conscious rabbits obtained without the need for human interactions using the AWDS are feasible and provide reproducible results.

Keywords: IOP, pressure transducer, wireless, MEMS, implant, intraocular

\section{Introduction}

Currently, intraocular pressure (IOP) measurement in animals is performed using handheld tonometers that require animal immobilization or sedation. The main disadvantages of these techniques are the use of indirect methods to measure IOP, the induced animal stress that can result in artificial IOP elevation, and the use of sedatives that can lower IOP. ${ }^{1,2}$ Alternatively, telemetric measurement in undisturbed rabbits were previously attempted in the late 1990s using telemetric transducers implanted subcutaneously on the dorsal neck, between the scapulae. ${ }^{1,3}$ These sensors were connected to the eye using a fluid-filled catheter. Both studies demonstrated diurnal rhythm in IOP, with rising IOP in night hours and falling IOP during the day hours. However, both arrangements required extraocular implantation of the transducer, raising issues about the practicality of the procedure and the possible long-term risk for infection. 
Recent advances in electronics and biomaterials have enabled the use of more sophisticated, miniaturized, and completely implantable IOP transducers for evaluating glaucoma drugs, which aim to reduce IOP. ${ }^{4-6}$ In 2000, a free-standing intraocular silicone implant, encapsulated into a polydimethylsiloxane polymer, was implanted for IOP measurements in conscious rabbits. ${ }^{7}$ The authors proposed that this device could serve as a functioning model of a telemetric IOP sensor for integration into an artificial intraocular lens, exhibiting a 0.9 to 0.99 correlation to pneumatonometry reading. In a more recent study, ${ }^{8}$ an existing implantable pressure transducer was used for high frequency continuous IOP measurements in nonhuman primates. The transducer was fixated at the lateral orbital wall, and a 23-gauge silicone tube was used to deliver aqueous humor from the anterior chamber to a fluid reservoir on the intraorbital side of the transducer. The extraocular part of the transducer was connected via a wire to the data acquisition and transmitter unit, which was implanted in the abdominal muscle wall. Continuous IOP measurements were acquired for 4 consecutive days before failure of the transducer.

Recently, our group implanted a fully encapsulated IOP transducer in rabbit eyes. ${ }^{9}$ The novelty of this device was based on the integration of the electronics, such as the pressure transducer, transmitter antenna, and power electronics, on a chip that was implanted into the eye and required no further implantable extraocular electronics. Despite the technological advancements and the simplification of the surgical procedure, human interaction for animal immobilization or sedation was required. IOP measurements were obtained using a handheld IOP reader, thus inducing IOP measurement artifacts and limiting the number of IOP measurements that could be taken per day. ${ }^{5,6,10}$

This study extends our previous work ${ }^{9}$ and presents an autonomous wireless data system (AWDS) that measures IOP without human interaction. The sensitivity and reliability of this experimental paradigm is assessed in vivo with and without the use of IOP-lowering agents.

\section{Materials and methods Animal IOP study}

The study was approved by the Massachusetts Eye and Ear Infirmary Animal Care Committee (Boston, MA, USA) and adhered to the Association for Research in Vision and Ophthalmology Statement for the Use of Animals. Implantation of a wireless IOP transducer was performed in a New Zealand White rabbit (Covance Inc., Dedham, MA, USA), housed in an individual cage under standard conditions of nutrition, humidity, and temperature. The rabbit was kept under alternating 12-hour light and 12-hour dark cycles. The wireless implantable IOP transducer (WIT) was implanted through a $10-\mathrm{mm}$ limbal incision and into the ciliary sulcus of the left eye following the extracapsular extraction of the crystalline lens.

The AWDS was comprised of a WIT (Implandata Ophthalmics GmbH, Hannover, Germany), a data acquisition unit, a coil antenna, and a camera motion sensor. The AWDS design allowed for autonomous IOP measurements, thus avoiding the animal's stress, sedation, and aberrant IOP recordings. The device integrated a pressure sensor, a temperature sensor, an identification encoder, an analogto-digital converter, and telemetry into a single implantable microchip. The outside diameter of the encapsulated implant was $11.3 \mathrm{~mm}$, with an inside diameter of $7 \mathrm{~mm}$, a thickness of $0.9 \mathrm{~mm}$, and a weight of $0.1 \mathrm{~g}$. The circular device was hermetically encapsulated in a biocompatible, platinumcured silicone rubber material that contains an open central aperture.

The pressure sensor was made by an array of plate capacitors in parallel configuration: one rigid plate and one flexible plate. The distance between the two plates derived the capacitive charge. Pressure acting on the capacitors caused plate deflection, thus changing the capacitance. This change in capacitance was analyzed and translated to IOP using a proprietary algorithm integrated in the data acquisition unit.

Communication between the implant and the data acquisition unit was achieved wirelessly using an external radio frequency antenna (communication link at $13.56 \mathrm{MHz}$ ). The data acquisition device was designed to acquire ten IOP measurements per second, average these measurements, and save the results to a memory card. Continuous IOP measurements were automatically performed as long as the eye was maintained within the effective antenna range. Measurements were triggered by a motion sensor connected to the data acquisition unit. Both the antenna and the motion sensor were placed in the cage pointing at the water bottle (Figure 1). When the rabbit drank, the motion sensor sent a triggering signal to the data acquisition unit to energize the implant and to acquire IOP measurements. The data was stored in a memory card within the data acquisition unit and contained a unique code with a time and date stamp. The data acquisition unit and the motion sensor were housed in a polymethylmethacrylate box for protection.

At the completion of each 5-week study cycle and during the 2-week washout period, the memory card was removed and replaced. Thus, human interaction was minimized to drop 


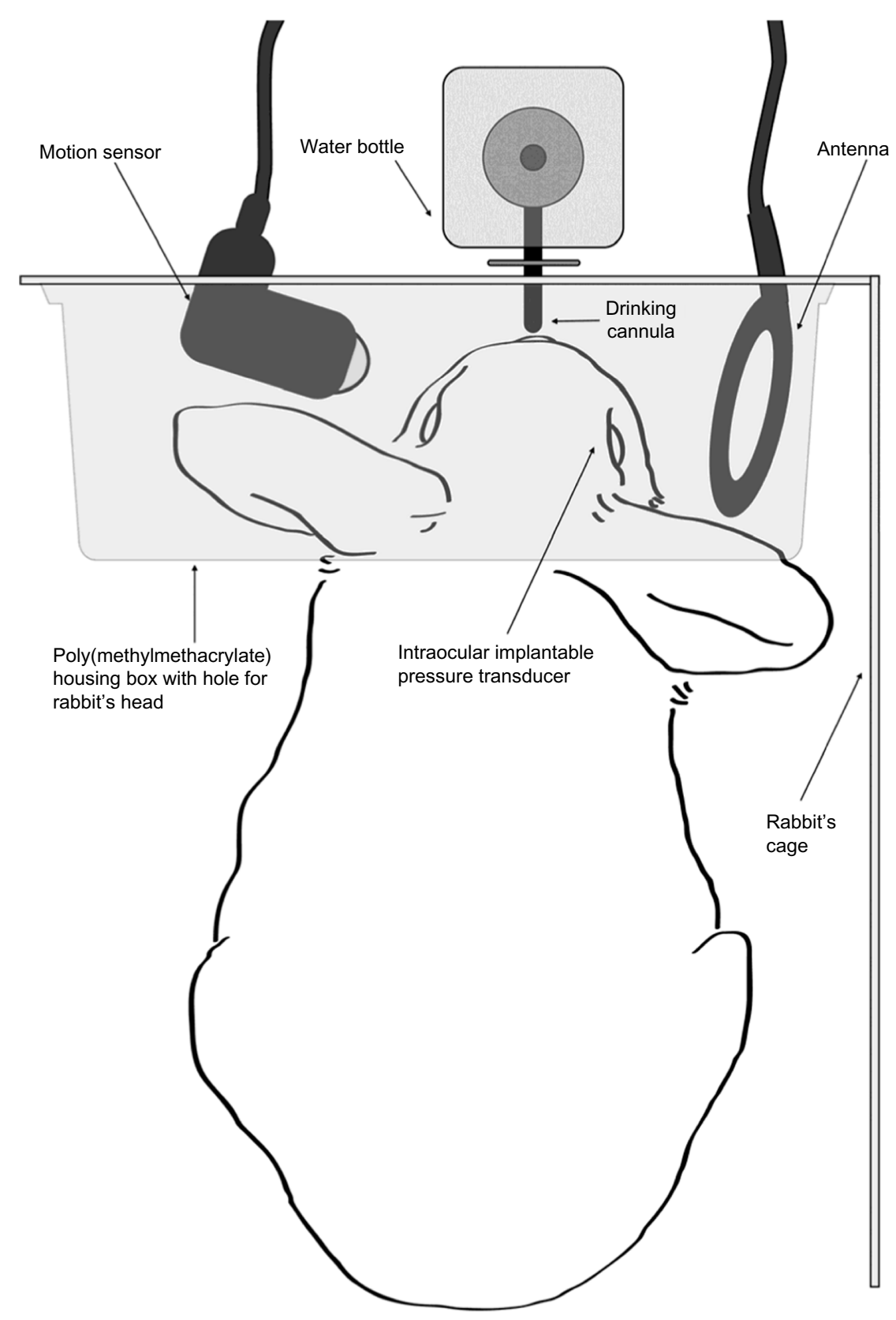

Figure I Schematic diagram of the wireless IOP acquisition technique.

Notes: A motion sensor (left) is used to trigger measurements each time the rabbit drinks from the water bottle (center). A wireless coil antenna (right), placed next to the eye with the implanted transducer, measures the IOP each time the motion sensor triggers a signal. All parts are housed in a polymethylmethacrylate box for protection and arranged in a way to optimize the quality of the signal. This technique provides autonomous IOP measurements, avoiding animal stress from human interaction and thus artificial IOP aberrations.

Abbreviation: IOP, intraocular pressure.

administration only, and IOP measurements were obtained without the need for anesthesia, caretaker involvement, and the stress of animal manipulation.

The IOP sensitivity of the proposed design was evaluated using two antiglaucoma agents, latanoprost, and dorzolamide. Each agent was administered separately, followed by a washout period of 1 month before introducing the second agent. A 1-month washout period was used based on the design of analogous published studies. ${ }^{11-15}$ Each study cycle (including weekends) involved 1 week of baseline IOP measurements without drop administration, 2 weeks of saline drop (vehicle) administration twice daily, 2 weeks of latanoprost $0.005 \%$ (Xalatan ${ }^{\circledR}$, Pfizer, New York, NY, USA) in the morning and saline in the evening, and 2 weeks of dorzolamide $2 \%$ (Trusopt $^{\circledR}$, Merck \& Co, Inc, Whitehouse Station, NJ, USA) one drop twice daily. Clinically, dorzolamide was 
administered twice a day and latanoprost was administered once a day, in the mornings. Saline was administered in the evenings to account for the confounding stress that could be induced by differences in drop administration between latanoprost and dorzolamide. Thus, the evening saline drop in the latanoprost study was added for consistency reasons, equalizing the frequency of human interaction with both drugs.

The mean IOP reduction by each agent was calculated using the following formula: ${ }^{16}$

$\mathrm{IOP}$ reduction $=\mathrm{IOP}_{\text {agent }}-\mathrm{IOP}_{\text {baseline }} \pm \mathrm{SD}_{\text {agent }}^{2}+\mathrm{SD}_{\text {baseline }}^{2}$

The intrasession IOP repeatability was assessed as follows: Several random time points were selected, all having at least eight or more consecutive IOP measurements within 1 minute period of time. IOP standard deviation (SD) was calculated for each time point, and the mean SD was calculated by averaging the SD from all time points. Since IOP is unlikely to change within a minute, IOP variations were attributed to the transducer's repeatability. ${ }^{17}$ All data were at least 2 hours after drop administration in order to secure drug effect and animal relaxation. ${ }^{18}$

\section{Statistical analysis}

All measurements were analyzed using Statistical Package for the Social Sciences, version 13.0 (IBM Corporation, Armonk, NY, USA). The normality of the sample was evaluated using Kolmogorov-Smirnov and Shapiro-Wilk tests. Quantitative variables were expressed as mean $\pm \mathrm{SD}$, and qualitative variables were expressed as frequencies and percentages. Analysis of variance (ANOVA) was used to evaluate differences in the IOP, and statistical significance was considered for $P$-value $<0.05$. Bonferroni correction was applied to reduce the alpha-level error to $P=0.02$, for multiple comparisons between baseline, vehicle, and treatment IOP. Polynomial equations (fifth order) were employed to reconstruct the circadian IOP rhythm from the point measurements.

\section{Results}

\section{Implantation of the transducer}

The wireless IOP transducer was implanted in the rabbit 18 months prior to this study, during which time the first study was performed. ${ }^{9}$ During this period, IOP measurements were routinely compared to intracameral manometry to ensure that there was no "drift" in IOP measurements, a problem frequently observed with IOP transducers. ${ }^{3,8,9}$
Three months prior to this study, the transducer was calibrated using intracameral manometry. The rabbit was anesthetized and a 21-gauge needle filled with balanced salt solution was inserted into the eye. The other end of the needle was connected to a pressure transducer (Harvard Apparatus, Holliston, MA, USA) measuring the IOP, as described previously. ${ }^{9}$ Additional measurements using TonoPen (Reichert Technologies, Depew, NY, USA) were performed 1 week prior to the study to ensure the functionality of the transducer. The general ocular health of the animal was assessed and recorded daily using the operating microscope. The intraocular structures appeared to be intact, with no obvious changes in the myelinated optic nerves between the eyes.

\section{IOP measurements}

In order to measure IOP, the data acquisition system and the motion sensor were securely mounted on the cage, with the latter pointing towards the water bottle (Figure 1). IOP measurements were autonomously triggered by the motion sensor each time the rabbit attempted to drink water from the bottle, thus avoiding human interaction and animal stress that could result in unwanted IOP fluctuations. Twenty-two percent of the IOP measurements were diurnal (7 am-7 pm) and $78 \%$ were nocturnal ( 7 pm-7 am) (Figure $2 \mathrm{~A}$ and B). A similar rhythm was also obtained with vehicle treatment (Figure 2C). Overall, diurnal IOP (median \pm standard error) was $11 \pm 0.138$ and nocturnal IOP was $12 \pm 0.102(P=0.563$; Mann-Whitney $U$ test). Diurnal IOP measurements were lower by $8.3 \%$ compared to nocturnal measurements, a percentile variation that is not statistically significant. Nocturnal activity was increased, as evidenced by the increased frequency in IOP measurements; this result is in concordance with previously published studies using telemetry. ${ }^{3,4}$ The mean intrasession IOP variability, assessed using vehicle treatment (saline drops), was $\pm 1.8 \mathrm{mmHg}$ (mean IOP measurements; $n=10$ ). Assuming that vehicle treatment should not change IOP unless stress is induced during measurements, vehicle IOP measurements were compared to the previously measured baseline IOP to elucidate the effect of eye drop administration in IOP. Average baseline IOP was $13.08 \pm 2.2 \mathrm{mmHg}$ ( $\mathrm{n}=99$ measurements) and IOP with vehicle treatment was $13.27 \pm 2.1 \mathrm{mmHg}$ ( $\mathrm{n}=185$ measurements), which was not significantly different $(P>0.45)$, suggesting that applying drops to the ocular surface had no influence on IOP outcome. Thus, further evaluation was undertaken, as explained on next page, to assess the ability of the AWDS to detect IOP variations. 

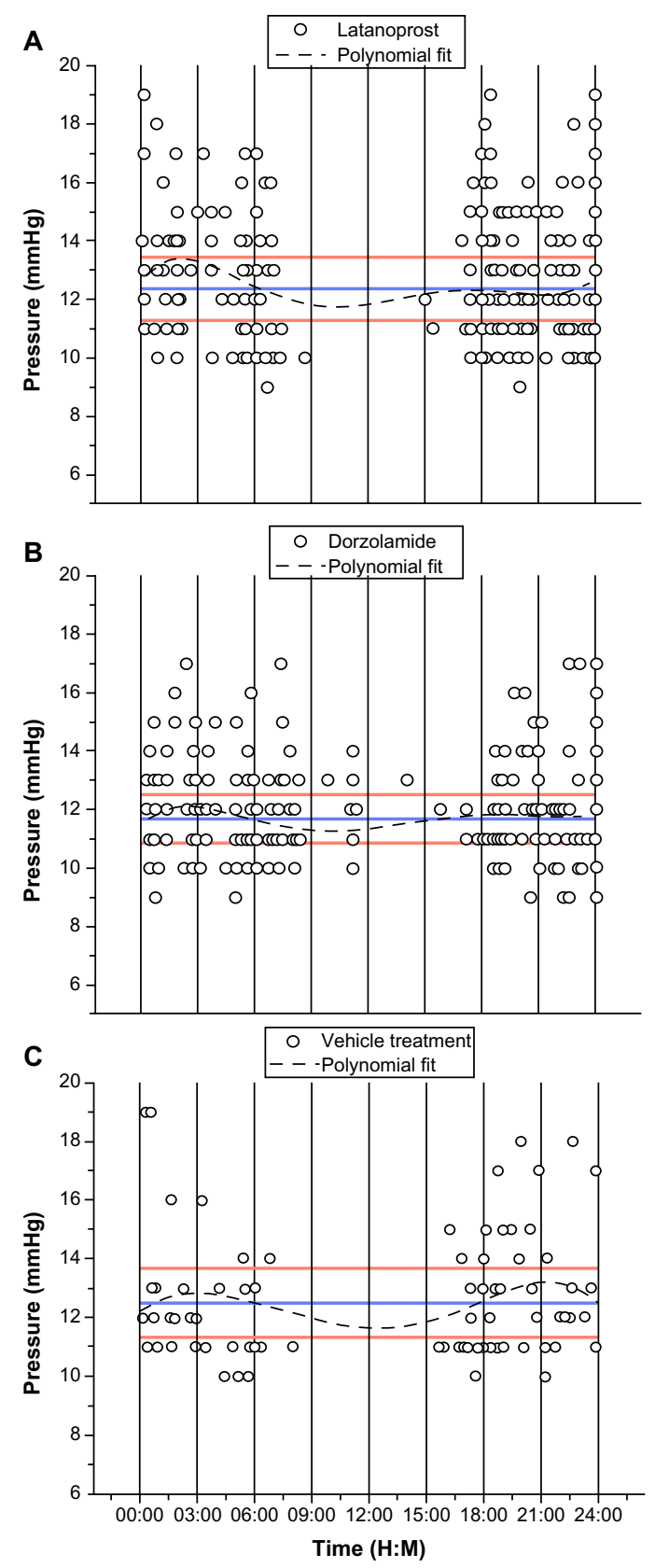

Figure 2 Circadian IOP variation with (A) latanoprost, (B) dorzolamide, and (C) vehicle administration.

Notes: The data points represent independent IOP measurements during 2 weeks of measurements. The dotted black line represents the polynomial fit (5th order) of the data set and the two red lines is the boundary between $I \pm$ standard deviation from IOP mean.

Abbreviations: $\mathrm{H}$, hours; IOP, intraocular pressure; $\mathrm{M}$, minutes.

\section{IOP measurements using antiglaucoma medication}

The sensitivity of the AWDS to detect IOP variations resulting from the application of latanoprost and dorzolamide was assessed separately. Each agent was given for 2 weeks, and IOP measurements were obtained throughout this period. The magnitude of IOP reduction with each agent was measured and compared to the corresponding baseline IOP. On average, 12 diurnal and 205 nocturnal IOP measurements were obtained with latanoprost, and 26 diurnal and 205 nocturnal measurements were obtained with dorzolamide. The frequencies in diurnal and nocturnal IOP measurements were comparable to baseline and vehicle treatment.

Both antiglaucoma agents caused significant IOP reduction compared to baseline. Use of latanoprost resulted in a $10 \%$ IOP reduction from baseline $(1.3 \pm 3.54 \mathrm{mmHg}$; $P<0.001$, ANOVA), and dorzolamide resulted in a $5 \%$ reduction (0.62 $\pm 2.22 \mathrm{mmHg} ; P<0.001$, ANOVA) (Table 1). Diurnal IOP was lower than nocturnal for both agents; however, this difference was not statistically significant (diurnal vs nocturnal IOP: latanoprost $P>0.318$; dorzolamide $P>0.689$ ) (Figure 3). The highest IOP measurements were recorded between $1 \mathrm{am}-3 \mathrm{am}$, and the lowest between 9 am-12 pm. Overall, IOP reduction with latanoprost was significantly higher compared to dorzolamide $(P<0.001)$.

\section{Discussion}

In this study, we introduce a novel technique for obtaining autonomous IOP measurements in rabbits. Telemetric IOP measurements were obtained over an 8-week period, thus preventing study-related IOP fluctuations due to animal restraints, sedatives, and anesthesia, ${ }^{1,19,20}$ which have been shown to influence the validity of IOP measurements. ${ }^{21}$ In addition, the implementation of this technique provides measurements of the nocturnal IOP, an otherwise laborious task using standard telemetry methods involving human aid. This study is a continuation of a previous published work using the aforementioned implantable transducer ${ }^{9}$ with the addition of a motion sensor for autonomous IOP measurements.

This pilot study was carried out in a single rabbit, and served as a proof of concept for the implementation of autonomous IOP measurements with telemetry. We assessed the repeatability of the technique by measuring the intrasession IOP variability. To do so, we calculated the SD for at least eight consecutive IOP measurements taken during a 60 -second interval. The mean intrasession IOP variability was $\pm 1.8 \mathrm{mmHg}$, a value lower than the variability seen with the Goldmann tonometer $( \pm 2.3-3.7 \mathrm{mmHg}),{ }^{21-24}$ ocular blood flow tonograph $( \pm 3.7 \mathrm{mmHg})$, TonoPen $( \pm 4.3 \mathrm{mmHg})$ or the Canon noncontact tonometer $( \pm 3.2 \mathrm{mmHg}) .{ }^{21}$ Our results suggest that AWDS exhibits good repeatability, with the ability to detect small IOP changes. Similar results would be impossible to obtain with traditional tonometers due to their higher intrasession variability. The ability to detect small IOP changes is critically important in animal research, 
Table I IOP reduction with placebo, latanoprost $0.005 \%$, and dorzolamide $2 \%$ compared to baseline

\begin{tabular}{|c|c|c|c|c|c|c|}
\hline & \multirow[t]{2}{*}{$\mathbf{N}$} & \multicolumn{2}{|l|}{$95 \% \mathrm{Cl}$ of mean } & \multirow[t]{2}{*}{ Mean } & \multirow[t]{2}{*}{ SD } & \multirow[t]{2}{*}{$P$-value compared to baseline IOP } \\
\hline & & Lower bound & Upper bound & & & \\
\hline Vehicle (saline) & 86 & -0.262 & 0.80 & 0.27 & 2.48 & $>0.5$ \\
\hline Latanoprost & 254 & -1.57 & -1.03 & -1.32 & 2.18 & $<0.00 I^{*}$ \\
\hline Dorzolamide & 284 & -0.81 & -0.44 & -0.62 & 1.55 & $<0.00 I^{*}$ \\
\hline
\end{tabular}

Notes: A summary of all IOPs taken throughout the study. *Statistically significant difference at 0.05 (comparison of the two groups).

Abbreviations: $\mathrm{Cl}$, confidence interval; $\mathrm{N}$, number of IOP measurements; IOP, intraocular pressure; SD, standard deviation.

where anatomical and biological differences compared to humans might change the magnitude of hypotonic efficacy of certain drugs. 25,26

The reliability of the technique was determined by comparing baseline and vehicle IOP. No significant difference was found between baseline and vehicle IOP, suggesting that no IOP artifacts were introduced with the implementation of AWDS. Previous studies using telemetry have shown that animal handling or sedation results in IOP artifacts, even with vehicle drops administration. ${ }^{3,9,27}$ In addition, blinking and forced eyelid opening during examination can cause transient increases in IOP, ${ }^{4}$ and investigator experience can influence the reliability of IOP measurements. ${ }^{24}$ In our study, IOP measurements were autonomously performed, thereby eliminating the need for animal handling or sedation. In addition, the reliability of the AWDS was further validated by the agreement between baseline and vehicle IOP measurements.

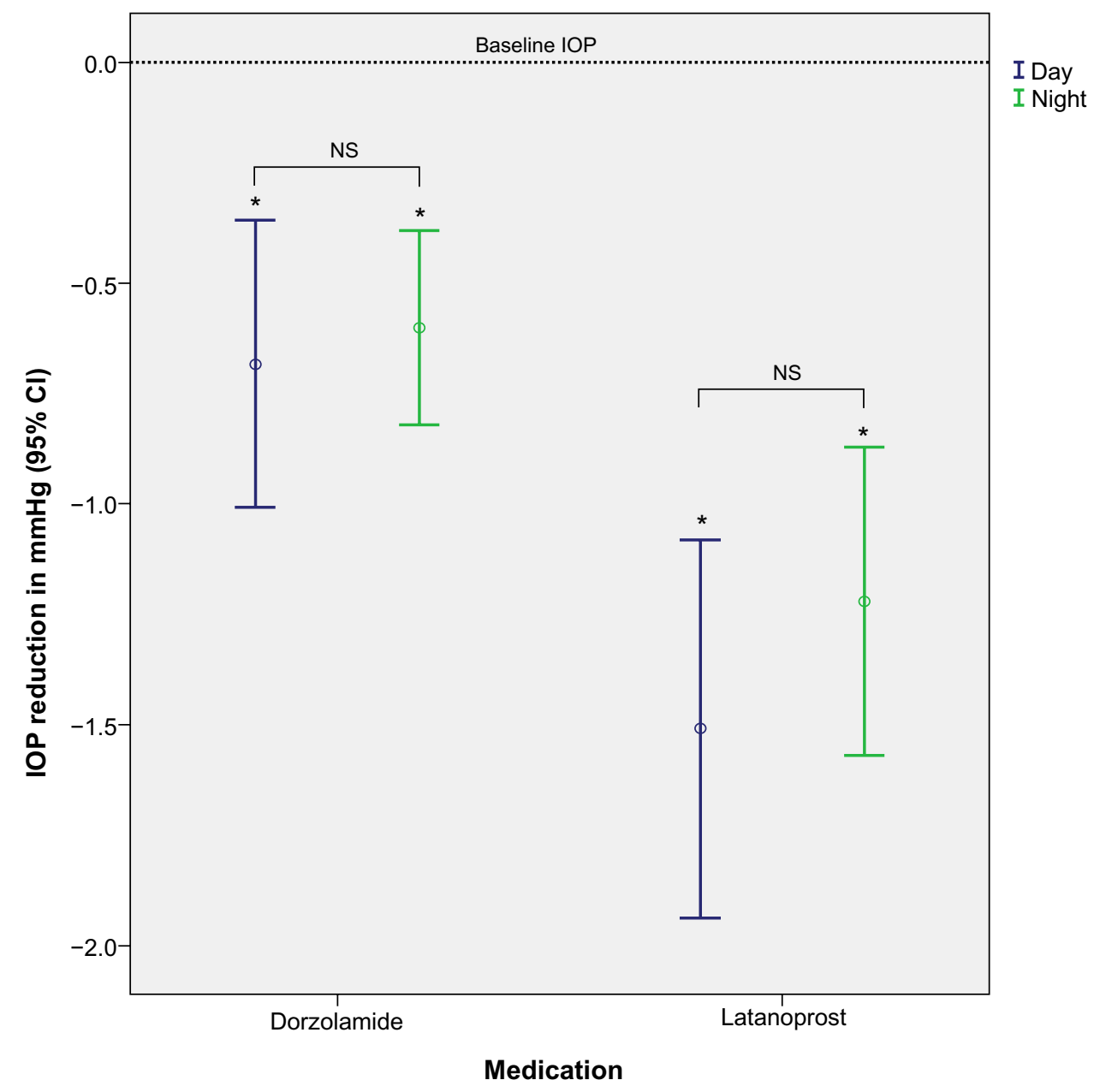

Figure 3 Diurnal and nocturnal IOP reduction with latanoprost and dorzolamide.

Notes: No difference between diurnal and nocturnal IOP with latanoprost $(P>0.318)$ or dorzolamide $(P>0.683)$. However, latanoprost causes significantly higher IOP reduction that dorzolamide in both diurnal $(P<0.003)$ and nocturnal $(P<0.002)$ IOP measurements. *Statistically significant difference compared to baseline IOP $(t$-test). Abbreviations: IOP, intraocular pressure; NS, nonstatistically significant difference ( $t$-test); $\mathrm{Cl}$, confidence interval. 
The sensitivity of the AWDS was evaluated in a normotensive rabbit using two IOP-lowering drugs: dorzolamide and latanoprost. In this study, dorzolamide caused an IOP reduction of $0.6 \mathrm{mmHg}(-5 \%, P<0.001)$, which is less than previously described $(-2.6 \mathrm{mmHg} \text { or }-17 \%)^{18}$ in normotensive rabbits and normotensive humans $(-3 \mathrm{mmHg}$ or $-19 \%) .{ }^{28}$ Latanoprost caused an IOP reduction of $1.3 \mathrm{mmHg}$ $(-10 \%, P<0.001)$, which is in agreement with a previous report of $1.5 \mathrm{mmHg}(-13 \%$ to $17 \%)$ in normotensive rabbits. ${ }^{27}$ The IOP-lowering effect of latanoprost is known to be species dependent. ${ }^{25,26}$ In a different study, latanoprost has been shown to cause an IOP reduction of $26 \%$ in normotensive humans, $16 \%$ in monkeys, and no change in rabbits. ${ }^{29}$

It is reasonable to believe that the reduced efficacy of latanoprost in rabbits can also be attributed to several comparative anatomical and biological differences, which are important considering the mechanism of action of the drug. Latanoprost is an ester analog of prostaglandin F2 $\alpha$ that reduces IOP by increasing uveoscleral outflow. ${ }^{14}$ Thus, anatomical difference in the uveal or binding affinity differences in the prostanoid receptors between species can have a significant impact on the hypotonic effect of latanoprost. Therefore, the reduced hypotonic effect of latanoprost could be explained by the fact that normotensive rabbits have less uveoscleral outflow $(3 \%-8 \%)^{30}$ than normotensive humans $(25 \%) .^{31,32}$ In addition, a reduced binding affinity by the prostanoid receptors in the nonpigmented ciliary epithelial cells has been reported in rabbits. ${ }^{33}$ Furthermore, the observed hypotonic effect in rabbits could be attributed to the secondary effect of nitric oxide production, known to induce hyperemia, increased blood flow of the anterior uvea, and IOP reduction. ${ }^{34}$

In this study, we compared the lower diurnal IOP to the peak nocturnal IOP (3-hour time intervals). The highest diurnal IOP change was observed between 9 am and $12 \mathrm{pm}$, with an $8.3 \%$ IOP reduction $(-1 \mathrm{mmHg})$, compared to nocturnal measurements between 1-3 am. This variation is not statistically significant, but is consistent with a previous study of rabbit diurnal IOP variation using pneumatonography, ${ }^{35}$ Interestingly, not all the rabbits in the pneumatonography study exhibited the same diurnal variations..$^{35}$ In comparison to a previous study that reported a wide range of diurnal IOP variation in rabbits, ${ }^{1,35-40}$ the lower diurnal IOP variation observed in our study could be attributed to several factors. For instance, the baseline IOP was low, and could be indicative of a lower plasma corticosteroid level. ${ }^{36,41}$ Eyes with higher IOPs exhibit elevated levels of corticosteroids in the plasma, ${ }^{36}$ which could relate to higher IOP variations. Elevated corticosteroid levels in the plasma can be due to animal stress; ${ }^{42-46}$ a confounding factor that was minimized in the present study using the AWDS. Another differentiating factor in our study is that measurements were obtained telemetrically in an awake, unrestrained rabbit when its head approached the water bottle, thus ensuring consistency in body posture and minimal sensory stimulation during measurements, which are known to cause transient IOP changes..$^{38-40,47,48}$ Our results are similar to other diurnal IOP studies performed in awake rabbits. ${ }^{35-37}$ In contrast, diurnal telemetric IOP measurements obtained in sleeping rabbits ${ }^{40}$ exhibited greater IOP variations. ${ }^{47-49}$ Elevated IOP in sleeping rabbits could be attributed to eyelid closure and increased abdominal pressure in the resting position, which have been shown to result in an IOP elevation of $5 \mathrm{mmHg}$. ${ }^{4-49}$

We conclude that the AWDS can provide IOP measurements in rabbits with high sensitivity and low intrasession IOP variability. Our technique overcomes previous limitations, thus providing reliable measurements critically important in the analysis of new antiglaucoma drugs. ${ }^{1,50}$ In addition, circadian IOP rhythm was obtained under similar diurnal and nocturnal conditions, including body posture, eyelid position, and minimal animal stress, thus decreasing IOP artifacts in our telemetric measurements. The implementation of the AWDS can improve the reliability of data acquisition and ameliorate the use of animal models in glaucoma research.

\section{Acknowledgments}

This work was supported by the Boston Keratoprosthesis funds. JBC is the recipient of a Research to Prevent Blindness (RPB) Career Development Award and is supported by the NEI/NIH 1K08EY019686. The authors would like to acknowledge Peter Mallen for his artwork contributions.

\section{Disclosure}

The authors report no conflicts of interest in this work.

\section{References}

1. Schnell CR, Debon C, Percicot CL. Measurement of intraocular pressure by telemetry in conscious, unrestrained rabbits. Invest Ophthalmol Vis Sci. 1996;37(6):958-965.

2. Gouws P, Moss EB, Trope GE, Ethier CR. Continuous intraocular pressure (IOP) measurement during glaucoma drainage device implantation. J Glaucoma. 2007;16(3):329-333.

3. McLaren JW, Brubaker RF, FitzSimon JS. Continuous measurement of intraocular pressure in rabbits by telemetry. Invest Ophthalmol Vis Sci. 1996;37(6):966-975. 
4. Percicot CL, Schnell CR, Debon C, Hariton C. Continuous intraocular pressure measurement by telemetry in alpha-chymotrypsin-induced glaucoma model in the rabbit: effects of timolol, dorzolamide, and epinephrine. J Pharmacol Toxicol Methods. 1996;36(4):223-228.

5. Pajic B, Pajic-Eggspuchler B, Haefliger I. Continuous IOP fluctuation recording in normal tension glaucoma patients. Curr Eye Res. 2011; 36(12):1129-1138.

6. Sehi M, Flanagan JG, Zeng L, Cook RJ, Trope GE. The association between diurnal variation of optic nerve head topography and intraocular pressure and ocular perfusion pressure in untreated primary openangle glaucoma. J Glaucoma. 2011;20(1):44-50.

7. Walter P, Schnakenberg U, vom Bögel G, et al. Development of a completely encapsulated intraocular pressure sensor. Ophthalmic Res. 2000;32(6):278-284.

8. Downs JC, Burgoyne CF, Seigfreid WP, Reynaud JF, Strouthidis NG, Sallee V. 24-hour IOP telemetry in the nonhuman primate: implant system performance and initial characterization of IOP at multiple timescales. Invest Ophthalmol Vis Sci. 2011;52(10): 7365-7375.

9. Todani A, Behlau I, Fava MA, et al. Intraocular pressure measurement by radio wave telemetry. Invest Ophthalmol Vis Sci. 2011;52(13): 9573-9580.

10. Mansouri K, Weinreb R. Continuous 24-hour intraocular pressure monitoring for glaucoma - time for a paradigm change. Swiss Med Wkly. 2012;142:w13545.

11. Parrish RK, Palmberg P, Sheu WP; XLT Study Group. A comparison of latanoprost, bimatoprost, and travoprost in patients with elevated intraocular pressure: a 12-week, randomized, masked-evaluator multicenter study. Am J Ophthalmol. 2003;135(5):688-703.

12. Daull P, Buggage R, Lambert G, et al. A comparative study of a preservative-free latanoprost cationic emulsion (Catioprost) and a BAKpreserved latanoprost solution in animal models. J Ocul Pharmacol Ther. 2012;28(5):515-523.

13. Gagliuso DJ, Wang RF, Mittag TW, Podos SM. Additivity of bimatoprost or travoprost to latanoprost in glaucomatous monkey eyes. Arch Ophthalmol. 2004;122(9):1342-1347.

14. Perry CM, McGavin JK, Culy CR, Ibbotson T. Latanoprost: an update of its use in glaucoma and ocular hypertension. Drugs Aging. 2003;20(8):597-630.

15. Harris A, Migliardi R, Rechtman E, Cole CN, Yee AB, Garzozi HJ. Comparative analysis of the effects of dorzolamide and latanoprost on ocular hemodynamics in normal tension glaucoma patients. Eur $J$ Ophthalmol. 2003;13(1):24-31.

16. Grégoire S. Variance. 5th ISTA seminar on statistics; 1999. Available from: http://www.seedtest.org/upload/cms/user/Variance.pdf. Accessed February 6, 2013.

17. Sullivan-Mee M, Gerhardt G, Halverson KD, Qualls C. Repeatability and reproducibility for intraocular pressure measurement by dynamic contour, ocular response analyzer, and Goldmann applanation tonometry. J Glaucoma. 2009;18(9):666-673.

18. Reitsamer HA, Bogner B, Tockner B, Kiel JW. Effects of dorzolamide on choroidal blood flow, ciliary blood flow, and aqueous production in rabbits. Invest Ophthalmol Vis Sci. 2009;50(5):2301-2307.

19. Ding C, Wang P, Tian N. Effect of general anesthetics on IOP in elevated IOP mouse model. Exp Eye Res. 2011;92(6):512-520.

20. Ghaffari MS, Moghaddassi AP. Effects of ketamine-diazepam and ketamine-acepromazine combinations on intraocular pressure in rabbits. Vet Anaesth Analg. 2010;37(3):269-272.

21. Tonnu PA, Ho T, Sharma K, White E, Bunce C, Garway-Heath D. A comparison of four methods of tonometry: method agreement and interobserver variability. Br J Ophthalmol. 2005;89(7): $847-850$.

22. Cheng J, Salam T, Russell PJ, Heath DG, Kotecha A. Dynamic contour tonometer and Goldmann applanation tonometer performance in a developing world setting: intraocular pressure measurement acquisition and precision. J Glaucoma. 2013.
23. García-Resúa C, Pena-Verdeal H, Miñones M, Giraldez MJ, Yebra-Pimentel E. Reliability of the non-contact tono-pachymeter Tonopachy NT-530P in healthy eyes. Clin Exp Optom. 2013;96(3): 286-294.

24. Kotecha A, White E, Schlottmann PG, Garway-Heath DF. Intraocular pressure measurement precision with the Goldmann applanation, dynamic contour, and ocular response analyzer tonometers. Ophthalmology. 2010;117(4):730-737.

25. Stjernschantz JW. From PGF(2alpha)-isopropyl ester to latanoprost: a review of the development of xalatan: the Proctor Lecture. Invest Ophthalmol Vis Sci. 2001;42(6):1134-1145.

26. Serle JB, Wang RF, Mittag TW, Shen F, Podos SM. Effect of pilocarpine $4 \%$ in combination with latanoprost $0.005 \%$ or 8 -iso prostaglandin E2 $0.1 \%$ on intraocular pressure in laser-induced glaucomatous monkey eyes. J Glaucoma. 2001;10(3):215-219.

27. Dinslage $S$, McLaren J, Brubaker R. Intraocular pressure in rabbits by telemetry II: effects of animal handling and drugs. Invest Ophthalmol Vis Sci. 1998;39(12):2485-2489.

28. Grueb M, Rohrbach JM. Effect of timolol on central corneal thickness. Eur J Ophthalmol. 2013;23(6):784-788.

29. Ishii K, Tomidokoro A, Nagahara M, et al. Effects of topical latanoprost on optic nerve head circulation in rabbits, monkeys, and humans. Invest Ophthalmol Vis Sci. 2001;42(12):2957-2963.

30. Nilsson SF. The uveoscleral outflow routes. Eye (Lond). 1997;11 (Pt 2): 149-154.

31. Johnson TV, Fan S, Camras CB, Toris CB. Aqueous humor dynamics in exfoliation syndrome. Arch Ophthalmol. 2008;126(7):914-920.

32. Patel SS, Spencer CM. Latanoprost. A review of its pharmacological properties, clinical efficacy and tolerability in the management of primary open-angle glaucoma and ocular hypertension. Drugs Aging. 1996;9(5):363-378.

33. Bhattacherjee P, Jacobs N, Coca-Prados M, Paterson C. Identification of prostanoid receptors in rabbit non-pigmented ciliary epithelial cells. Exp Eye Res. 1996;62(5):491-498.

34. Astin M, Stjernschantz J, Selén G. Role of nitric oxide in PGF2 alphainduced ocular hyperemia. Exp Eye Res. 1994;59(4):401-407.

35. Tsukahara S, Phillips CI, Gore SM. Rabbit diurnal ocular tension variations. Ophthalmic Res. 1992;24(6):372-375.

36. Weitzman ED, Henkind P, Leitman M, Hellman L. Correlative 24-hour relationships between intraocular pressure and plasma cortisol in normal subjects and patients with glaucoma. $\mathrm{Br} J$ Ophthalmol. 1975;59(10):566-572.

37. Vareilles P, Conquet P, Le Douarec JC. A method for the routine intraocular pressure (IOP) measurement in the rabbit: range of IOP variations in this species. Exp Eye Res. 1977;24(4):369-375.

38. Liu JH, Dacus AC. Endogenous hormonal changes and circadian elevation of intraocular pressure. Invest Ophthalmol Vis Sci. 1991;32(3):496-500.

39. Bar-Ilan A. Diurnal and seasonal variations in intraocular pressure in the rabbit. Exp Eye Res. 1984;39(2):175-181.

40. Collins CC. Evoked pressure responses in the rabbit eye. Science. 1967;155(3758):106-108.

41. Eleftheriou BE. Circadian rhythm in blood and brain biogenic amines and other biochemical changes in rabbits. Brain Res. 1974;75(1): 145-152.

42. Rosochacki SJ, Piekarzewska AB, Połoszynowicz J, Sakowski T. The influence of restraint immobilization stress on the concentration qf bioamines and cortisol in plasma of Pietrain and Duroc pigs. J Vet Med A Physiol Pathol Clin Med. 2000;47(4):231-242.

43. Noller CM, Szeto A, Mendez AJ, et al. The influence of social environment on endocrine, cardiovascular and tissue responses in the rabbit. Int J Psychophysiol. 2013;88(3):282-288.

44. Dalin AM, Magnusson U, Häggendal J, Nyberg L. The effect of transport stress on plasma levels of catecholamines, cortisol, corticosteroidbinding globulin, blood cell count, and lymphocyte proliferation in pigs. Acta Vet Scand. 1993;34(1):59-68. 
45. Gebhardt-Henrich SG, Fischer K, Hauzenberger AR, Keller P, Steiger A. The duration of capture and restraint during anesthesia and euthanasia influences glucocorticoid levels in male golden hamsters. Lab Anim (NY). 2007;36(4):41-46.

46. Panossian A, Hambardzumyan M, Hovhanissyan A, Wikman G. The adaptogens rhodiola and schizandra modify the response to immobilization stress in rabbits by suppressing the increase of phosphorylated stress-activated protein kinase, nitric oxide and cortisol. Drug Target Insights. 2007;2:39-54.

47. Aref AA. What happens to glaucoma patients during sleep? Curr Opin Ophthalmol. 2013;24(2):162-166.
48. Singleton CD, Robertson D, Byrne DW, Joos KM. Effect of posture on blood and intraocular pressures in multiple system atrophy, pure autonomic failure, and baroreflex failure. Circulation. 2003;108(19): 2349-2354.

49. Roberts JR and Hedges JR. Clinical procedures in emergency medicine. Sanders, an imprint of Elsevier Inc., Philiadelpia, PA. 2010. ISBN 9781-4160-3623-4.

50. Elsheikh A, Gunvant P, Jones SW, Pye D, Garway-Heath D. Correction factors for Goldmann Tonometry. J Glaucoma. 2013;22(2):156-163.
Clinical Ophthalmology

\section{Publish your work in this journal}

Clinical Ophthalmology is an international, peer-reviewed journal covering all subspecialties within ophthalmology. Key topics include: Optometry; Visual science; Pharmacology and drug therapy in eye diseases; Basic Sciences; Primary and Secondary eye care; Patient Safety and Quality of Care Improvements. This journal is indexed on

Submit your manuscript here: http://www.dovepress.com/clinical-ophthalmology-journal

\section{Dovepress}

PubMed Central and CAS, and is the official journal of The Society of Clinical Ophthalmology (SCO). The manuscript management system is completely online and includes a very quick and fair peer-review system, which is all easy to use. Visit http://www.dovepress.com/ testimonials.php to read real quotes from published authors. 